\title{
Usos políticos del sufrimiento en el Vía Crucis del Migrante, Ixtepec, Oaxaca
}

\author{
The Politic Uses of Suffering on the Via Crucis of the \\ Migrant, Ixtepec, Oaxaca
}

\author{
Yuri Arón Inocente Escamilla \\ El Colegio de Michoacán \\ hiacinto@gmail.com \\ DOI: I0.2490I/rehs.v40i157.339
}

\section{(c) (i) (9)}

Usos políticos del sufrimiento en el Vía Crucis del Migrante, Ixtepec, Oaxaca por Yuri Arón Inocente Escamilla se distribuye bajo una Licencia Creative Commons AtribuciónNoComercial 4.0 Internacional.

Fecha de recepción: 2 de agosto de 2017

Fecha de aprobación: 6 de octubre de 2108

\section{RESUMEN:}

En la representación del Vía Crucis del Migrante que se realizó en la ciudad de Ixtepec, Oaxaca, en el año 2or6, encuentro que es un marco político-religioso heurístico para explorar los usos políticos del sufrimiento. Este sufrimiento es causado por fuerzas sociales e institucionales que infligen violencias a los migrantes. Siguiendo las ideas de Didier Fassin, analizo cómo el cuerpo sobre el cual se ejercen violencias se expone en el vía crucis para apelar al reconocimiento de sus derechos políticos. Los diferentes tipos de violencia que sufren los migrantes centroamericanos están representados de manera narrativa durante la representación para hacer visibles sus historias personales, sus problemas y la violencia que enfrentaron en su camino. El objetivo de esta representación narrativa es el reconocimiento de sus derechos.

Palabras clave:

Usos políticos del sufrimiento, Vía Crucis del Migrante, narrativas sobre violencia, marcos, representaciones. 


\section{ABSTRACT:}

While observing the performance of the Vía Crucis of the migrant in Ixtepec, Oaxaca, in 2oi6, I realized that it provided a sociopolitical and heuristic framework for exploring the political uses of suffering. This specific form of suffering is perpetrated by the social and institutional forces that inflict violence on migrants. Following Didier Fassin's lead, I analyze how the violated body is exposed in the Vía Crucis of the migrant as a way to reclaim migrants' political rights. During the Via Crucis of the migrant, the different kinds of violence that Central Americans migrants suffer are represented narratively in order to make visible their personal histories, their problems and the violence they confront during their sojourn. The objective of this narrative representation is to gain recognition of their rights.

Keywords:

Politic uses of suffering, migrant's Vía Crucis, narratives of violence, framing, representation.

\section{Introducción ${ }^{\underline{1}}$}

"Mi nombre es Rodolfo, tengo 35 años de edad, con mi hermano salimos de El Salvador. Dejamos a nuestra familia y a todos los amigos". Con esas palabras se presentó Rodolfo; lo entrevisté durante el segundo trabajo etnográfico que realicé en el albergue Hermanos en el Camino, en Ixtepec, Oaxaca, en el año 2016.

Rodolfo antes vivía en el departamento de Santa Ana, un lugar fronterizo con Guatemala. El 29 de enero de 2016 decidió viajar hacia Estados Unidos junto con su hermano; se internaron a México por Tecún Umán, ciudad guatemalteca perteneciente al departamento de San Marcos; burlaron la seguridad fronteriza y siguieron moviéndose hasta la ciudad de Arriaga, estado de Chiapas. Los costos de su viaje no sólo incluían el transporte, sino también las extorsiones de los agentes policiales para dejarlos transitar.

Al llegar a Santo Domingo Zanatepec, estado de Oaxaca, los asaltaron tres hombres armados con machetes; los despojaron de sus pertenencias y los golpearon. Después de este incidente, llegaron al albergue Hermanos en el Camino; un voluntario los entrevistó en el lugar y les preguntó si habían sido víctimas de violencia, ambos manifestaron que sí. Consecutivamente, el voluntario les explicó que tenían derecho a interponer una denuncia ante la fiscalía de migración en la ciudad de Ixtepec, exponiendo que habían sido víctimas de robo, extorsiones y golpes. Por medio de la denuncia, el fiscal redactaría un acta para declarar que habían sido victimados; con el acta podrían solicitar una visa por razones humanitarias en las oficinas del Instituto Nacional de Migración de Salina Cruz. Cuando realicé la entrevista, Rodolfo junto a su hermano permanecían en el albergue esperando la visa, además, en pocos días se celebraría el Vía Crucis del Migrante y él se preparaba como uno de los lectores de algunas estaciones.

El Vía Crucis del Migrante, de acuerdo a Alejandro Solalinde,, tiene explicación en las palabras que una mujer mixteca le dijo: "ya es domingo de resurrección, pero viera que nosotros todavía seguimos en nuestro Viernes Santo". ${ }^{3}$ La oración "todavía seguimos viviendo nuestro Viernes 
Santo" es un tropo que Alejandro y otros activistas utilizan para explicar que en el Vía Crucis del Migrante no celebra una resurrección; más bien, "seguir viviendo el Viernes Santo" es una narrativa que enuncia la continuidad de la violencia que experimentan los migrantes. En su discurso, los migrantes personifican el rostro del dolor al volverse objeto de discriminaciones, exclusión social, violencia y muerte en sus países de origen y, durante su tránsito por México; ellos se asemejan a Jesús, quien padeció abusos y expresiones de violencia durante su camino. La imagen del camino en que los migrantes personifican el rostro del sufrimiento, introduce los propósitos de este documento: cómo las narrativas sobre experiencias de sufrimiento de los migrantes son escenificadas y tienen usos políticos en el Vía Crucis del Migrante en Ixtepec; mostrando que sus derechos humanos son violentados, buscan la sensibilidad y solidaridad social de algunos públicos en Ixtepec, Ciudad de México y de los agentes de migración mexicana. ${ }^{4}$

En este documento analizaré dos actos discursivos para explicar cómo en las acciones situadas argumentan y producen acciones políticas. El primer acto discursivo se refiere a la participación de Rodolfo como lector en la primera estación. En el segundo acto, expondré el discurso con el que cierra Wilmer el Vía Crucis del Migrante. Los dos discursos son importantes para comprender los usos políticos que hacen del sufrimiento en espacio-tiempo específicos.

Las ideas que expondré en el artículo están divididas en las siguientes secciones: advertencias; los encuadres: las narrativas del sufrimiento; pensamientos que nutren el Vía Crucis del Migrante en la ciudad de Ixtepec, Oaxaca; los usos políticos del sufrimiento en el Vía Crucis del Migrante: los actos de las estaciones; la ventana: los actos y las narrativas y; reflexiones.

\section{Advertencias}

La investigación se realizó durante dos trimestres: el primero, en julio-septiembre del 20r5; el segundo, en enero-marzo del 20i6. En mis estancias empleé el método etnográfico de observación participante para trabajar con los migrantes salvadoreños, guatemaltecos y hondureños que llegaban al albergue Hermanos en el Camino, ciudad de Ixtepec, Oaxaca. El albergue se fundó el 7 de febrero del año 2007, como estrategia para responder a los problemas relacionados con la violencia institucional y social que se inflige a los hombres, mujeres y jóvenes migrantes indocumentados de origen salvadoreño, guatemalteco y hondureño.

Trabajé con hombres, mujeres y jóvenes que estaban en proceso de regularización migratoria esperando una visa por razones humanitarias. Accedí a ellos por medio de mi involucramiento como voluntario. Mi trabajo consistió en acompañarlos a la fiscalía del migrante, cocinar para ellos, organizar y participar junto a ellos en los torneos deportivos y labores de limpieza. Las edades de los hombres rondan entre los 20-58 años; la edad de las mujeres oscilaba entre los 2540 y los jóvenes entre I4-I8 años de edad.

Los encuadres: las narrativas del sufrimiento

Por sufrimiento comprendo al "ensamblaje de problemas humanos que tienen sus orígenes y sus consecuencias en las heridas devastadoras que las fuerzas sociales infligen a la experiencia 
humana" (Das 2008a, 453), estas heridas no sólo refieren a situaciones de muertes, también, al igual que la experiencia de Rodolfo, las agresiones que vivieron son una manera de comprender las interacciones con distintas fuerzas sociales que han posibilitado la construcción de mecanismos para infligir violencia como una forma de sufrimiento. Siguiendo a Didier Fassin en "Gobernar por los cuerpos, políticas de reconocimiento hacia los pobres y los inmigrantes" (2005), entenderé aquí por usos políticos del sufrimiento, las maneras en que el cuerpo y los discursos sobre sufrimientos son puestos en escena, con el objeto de hacerse valer en determinado momento de su historia (Fassin 2005, 202). De acuerdo a esta idea, el cuerpo, sobre el cual se ejercen las violencias, es el que da derechos (Fassin 2005, 204). La experiencia de Rodolfo es un ejemplo, él discursivamente expuso los agravios que vivió, primero, a los voluntarios del albergue, después, al fiscal y a los agentes de migración mexicana, éstas fueron las direcciones que siguió para solicitar la residencia por razones humanitarias. De esa manera, cuando se enuncia el problema por medio de narrativas y la puesta en escena de su cuerpo, se produce el comienzo de una relación donde pretenden comunicar el problema, "no su final" (Das 2008b, 358).

Las narrativas que se enunciaron en el Vía Crucis del Migrante, las empleo como un estilo de género discursivo (Bajtín I982,255), es decir, como esferas donde se hace uso de la lengua elaborando ciertos mecanismos de estabilidad que les permite enunciar algo en dirección a distintos públicos. Como Bajtín lo ha nombrado, cada estilo se vincula a temáticas que se elaboran para establecer una comunicación entre el hablante y otros participantes; las narrativas político-religiosas que se pronuncian a favor del respeto a los derechos de los migrantes salvadoreños, hondureños y guatemaltecos en contra de las violencias que viven, tienen un estilo de enunciado político-religioso que se dirige a comunicar una temática: la continuidad de narrativas de sufrimiento. De esta manera, los discursos que se enuncian no sólo describen un problema, al decirlo están representando acciones (Austin 1996,47) que buscan que sus derechos vulnerados sean respetados.

Estas narrativas son actos situados, que están dentro de marcos que funcionan como sistemas interpretativos, con el propósito de identificar o acuñar aquello que ocurre dentro de su espacio vital y en el mundo en general. Este sistema interpretativo resulta de una perspectiva situacional, donde las personas ordenan, perciben, identifican sucesos específicos de sus experiencias (Verdugo y Gómez 2006). Por ejemplo, el momento en que el voluntario del albergue preguntó a Rodolfo si había sido víctima responde a una situación. Una situación que se caracteriza por la selección de un evento, éste se dirige a una acción comunicativa: hablar del momento del robo e interponer una denuncia ante la fiscalía del migrante. La selección implica recordar una experiencia que en ese momento está siendo dotada de sentidos, tanto por Rodolfo, su hermano y el voluntario. La situación no sólo se dirige a recordar cómo pasaron las cosas, lo relevante en la narrativa de Rodolfo es cómo se perciben y explican contextos políticos más amplios.

En estos contextos amplios, me refiero a los espacios donde se les inflige violencia, en los diferentes actos del vía crucis se enmarcan estas situaciones para explicar que la violencia social e institucional que experimentan los migrantes indocumentados es una manera de violentar sus derechos. Esto cobra sentido cuando observamos que para México el flujo de los migrantes 
centroamericanos constituye el $90 \%$, desde mediados de la década de 1990 ha venido incrementando, aunque a la mitad de la década del 2000 el número de migrantes que pasa por México disminuyó; se estima que durante el año 2010 la reducción fue de 70 \% (Salazar $\underline{20 I 2}$, Calleros 20I3). Junto a la disminución, los secuestros y asesinatos de migrantes se hicieron evidentes durante el año de 2006 (Calleros 2013, 317). El 24 de agosto de 20Io, el asesinato de 72 migrantes centroamericanos en San Fernando Tamaulipas evidenció aún más la vulnerabilidad de los migrantes y mostró que representan fuentes alternativas de ingresos para el crimen organizado (Izcara 20I2, Calleros 20I3, Vogt 20I3). Un año más tarde, en el mismo lugar se exhumaron 194 cadáveres, muchos de ellos eran migrantes que se transportaban en autobús (Izcara 20I2, 7).

Hay muchas maneras para explicar estos problemas, aquí haré referencia a dos marcos interpretativos: pensamientos que nutren el Vía Crucis del Migrante y los usos políticos del sufrimiento en el Vía Crucis del Migrante. El primero hace referencia a las ideas políticoreligiosas desarrolladas en las reformas conciliares de 1968 y posteriormente en la CELAM, Aparecida en 2007 , donde la figura del migrante se convierte en sujeto sufriente que necesita ser enunciado políticamente. El marco del Vía Crucis del Migrante es una representación situada. Expondré dos actos donde la experiencia de los migrantes y activistas se sitúa para explicar paisajes de violencias; además, los usos políticos del sufrimiento se accionan por medio de la representación corporal y los discursos político-religiosos que orientan las explicaciones en y sobre la violencia que experimentan transitando en la frontera sur de México.

Pensamientos que nutren el Vía Crucis del Migrante en la ciudad de Ixtepec, Oaxaca

En la ciudad de Ixtepec, el io de enero de 2007, ocurrió el último de los secuestros masivos de migrantes que habían llegado a la ciudad sobre la Bestia. Después de los incidentes, durante la Semana Santa de ese año, Alejandro Solalinde junto con otros activistas organizaron el primer Vía Crucis del Migrante que se representó en esta ciudad para denunciar el contexto de los secuestros.

En este escrito no caracterizaré este primer Vía Crucis del Migrante, más bien, expondré parte del pensamiento teológico que le da sustento. Aquí, considero importante empezar a introducir algunas distancias entre el vía crucis litúrgico y el Vía Crucis del Migrante para comprender algunas diferencias sobre las explicaciones y usos políticos que hacen los migrantes y activistas del sufrimiento.

El vía crucis litúrgico se originó en la Contrarreforma del Concilio de Trento entre los años 1545 y 1563 (Secalla 200I, I), se introdujo el valor penitencial para conmemorar la pasión de Cristo como fuente fundamental de la redención (Torrecillas 2009, 273). El sentido de la "Pasión de Cristo" cobró significado en la idea de sufrimiento; el creyente debía sufrir y escudriñar en la propia carne los mecanismos de la redención. En ese momento, la exaltación del cuerpo que sufre (Corbin 2005) y la exposición del dolor ante los ojos de los fieles contribuyó a una devoción centrada en el culto del cuerpo doliente (Gélis 2005. 33-34). La construcción del sufrimiento fue parte de procesos sociales, se revitalizó en el siglo XIX con la exhibición del cuerpo que pasó a 
ser esencial en la espiritualidad y moral basada en una cultura somática (Corbin 2005. 58), esto significó que las expresiones de dolor debían manifestarse de manera clara sobre el cuerpo. Las manifestaciones de dolor mostradas en el vía crucis litúrgico no son sólo una metáfora para explicar el movimiento secuencial de la vida, pasión, muerte y resurrección de Cristo, también se convirtió en el "acto litúrgico por excelencia de una espiritualidad que hurga en el sufrimiento y la mortificación de la carne la posibilidad de la misericordia". ${ }^{2}$ Una misericordia para la redención.

Los sentidos sobre el dolor y el sufrimiento que se enuncian en los Vía Crucis del Migrante, encontrarán los primeros puntos de referencia en la opción preferencial por los pobres que la Iglesia católica discutió durante el Concilio Vaticano II, en Medellín r968 y Puebla i979 (Casillas I 89 , I82). En estos eventos, se reafirmó la imagen del pueblo crucificado, se especifica que el mundo de pobreza en el que viven los más necesitados se relaciona con aspectos concretos de injusticias económicas, políticas y sociales. Estos elementos caracterizan al pueblo crucificado y el signo de los tiempos que no pueden ser entendidos sino es por ellos mismos (Sobrino 2009, Iq).

Si reflexionamos sobre la pastoral social que Alejandro Solalinde ha venido construyendo, podemos encontrar explicaciones para interpretar las distintas situaciones de los migrantes, sobre todo, si pensamos que los migrantes representan ese otro crucificado. Sin embargo, es hasta las Conferencias Episcopales Latinoamericanas (CELAM) celebrada en Aparecida, Brasil, durante el año 2007 cuando se discutió la imagen del migrante como el sujeto político caracterizado por injusticias sociales. En el documento conclusivo de las Conferencias, se sitúa uno de los lineamientos pastorales vigentes que coinciden con el discurso y respuestas teológicas que Alejandro Solalinde emplea para justificar su obra pastoral con los migrantes. Al interior del octavo capítulo del documento conclusivo enfatizaron que los migrante son: "rostros sufrientes que nos duelen". Los migrantes aparecen dibujados como uno de muchos rostros que sufren, a la vez definieron los lineamientos que la Iglesia debía implementar en favor de los migrantes, con carácter para denunciar "los atropellos que sufren frecuentemente, como también el esfuerzo por incidir, junto a los organismos civiles, en los gobiernos de los países, para lograr una política migratoria que tenga en cuenta los derechos de las personas en movilidad" (CELAM 2008, 2I4).

En ambos vía crucis hay elementos que los conectan y a la vez los separan. En el litúrgico los significados de la vida, pasión, muerte y resurrección son valores de la trascendencia corporal. En contraparte, el Vía Crucis del Migrante describe la continuidad de la vida, pasión y muerte sin la existencia de una resurrección. Ambos vía crucis tienen acercamientos, uno de ellos, se relaciona con la exhibición social del cuerpo que ha soportado el dolor. Las distancias de cómo se valora el sufrimiento en el Vía Crucis del Migrante aparecen en el uso político-discursivo y cuando nos preguntamos ¿quiénes ocasionan este dolor? Encontraremos que detrás del dolor que se exhibe en el vía crucis litúrgico hay un sufrimiento que se autoinflige; en el Vía Crucis del Migrante el sufrimiento responde a situaciones sociales externas que les impone el dolor. Durante el diálogo, Alejandro mencionó que el vía crucis litúrgico debe entenderse con la condena de Jesús a la muerte: "ahí empieza su vía crucis, emprende su camino hacia la cruz. [...] 
el Viernes Santo litúrgico, guio a Jesús a la muerte, al morir, [...], el tercer día él resucita, se cierra el ciclo de la pascua". $\underline{6}$

Esta frase que enuncia Alejandro es una interpretación teológica y política a la vez. La reafirmación de los valores de la vida, pasión, muerte y resurrección es posible comprenderlos sólo través de la misericordia que enfatiza la necesidad de vivir los infortunios para acceder a las recompensas. Pero, a la vez, es un signo que se interpreta constantemente en cada contexto. El sufrimiento como un signo polifónico que es interpretado constantemente dará los sentidos políticos que las narrativas que los migrantes dicen en el vía crucis, como ejemplo vale mencionar los discursos que enunció Rodolfo en diferentes actos para mostrar, por medio del género político-religioso, que son objeto de injusticias sociales. Los usos políticos del sufrimiento no son sólo una caracterización para buscar la misericordia social, deben ser entendidos como una estrategia para presentarse a sí mismos y sus problemas. Siguiendo a Veena Das (2008b), este sufrimiento no es autoinfligido: es producto de un proceso en el que está implicada la sociedad. En estos contextos, ¿cómo se debe entender el Vía Crucis del Migrante? Durante una conversación con Alejandro, le pregunté sobre el significado del Vía Crucis del Migrante, me explicó que:

De acuerdo al calendario litúrgico, el sábado en la noche es cuando se abre la gloria, ahí dejamos el vía crucis y empezamos el tiempo de pascua, pero esto no sucede con los migrantes. Los migrantes, aunque sea domingo de resurrección, ellos siguen viviendo su Viernes Santo, siguen llevando su camino hacia la cruz. Esto es el fundamento teológico del Vía Crucis del Migrante; cuando decimos Vía Crucis del Migrante, estamos haciendo una migración de sentido, porque pasamos de la celebración histórica de Jesús al vía crucis que está viviendo la humanidad en general, todo aquel que sufre, así como los migrantes cuando son objeto de la violencia en sus lugares de origen, de tránsito y destino. ${ }^{7}$

El fundamento teológico que Alejandro Solalinde utiliza para explicar el Vía Crucis del Migrante manifiesta una "migración de sentidos". La migración consiste en mencionar similitudes; los migrantes centroamericanos, al igual que el Jesús bíblico, viven y caminan por espacios donde sus derechos son vulnerados. Pero, también, la frase ofrece diferencias teológicas con el acto litúrgico de la Iglesia católica, me refiero a los significados sobre cómo se valora la continuidad y representación del sufrimiento. La primera diferencia se debe comprender con el tropo "Viernes Santo"; aquí el sufrimiento parece un estado del que no se puede salir; el tiempo y el espacio narran sufrimientos que son continuos en la experiencia de los migrantes. El Vía Crucis del Migrante se transforma en un acto donde se enuncian políticamente estas continuidades.

La segunda diferencia se refiere a los valores que se busca representar en ambos vía crucis. En el acto litúrgico, los valores de la vida, pasión, muerte y resurrección enuncian los elementos centrales de la representación, visto de esa manera, traza una secuencia de temporalidad lineal donde existe un principio y un fin; pero, además, hurgan en el cuerpo de los fieles para recordarles que el sufrimiento es una manera para aspirar a la misericordia y la compasión. En 
el Vía Crucis del Migrante estos valores juegan como universos cíclicos, donde hay continuidades y fines que no siempre son claros para los migrantes. Además, se deben entender más allá de la acción compasiva que debe tenerse para los que sufren, incluso si se entiende como aquellas circunstancias relacionadas con el cuidado por el otro que muestra ser "un tema de nuestra época que, como bien lo han argumentado pensadores de la talla de Leonardo Boff (2012), Karen Armstrong (2011), Emmanuel Levinas (1995) y Enrique Dussel (2011), entre otros, responde a la inusitada crisis de la humanidad" (Hernández 20I4, 65). El Vía Crucis del Migrante debe comprenderse, por un lado, como un marco político-religioso en el que por medio del acto y los discursos el sufrimiento tiene usos políticos que se dirigen a diversos públicos, por otro, permite abordar la interpretación de paisajes sociales, políticos y las formas para comprender aspectos relacionados con la violencia, la perdida y el duelo (Peterson y Peterson 2008, 512).

Los usos políticos del sufrimiento en el Vía Crucis del Migrante: los actos de las estaciones

Viernes Santo. Todos estábamos despiertos la mañana del 25 de marzo de 20i6. El calor de Ixtepec acrecentaba; abrasaba todo el albergue Hermanos en el Camino. Las siete, aún no amanece, el sudor camina por nuestros cuerpos; Josefina, una misionera católica de la comunidad el Ángel de la Guarda que servía como voluntaria permanente en el albergue, nos ha recordado que a las ocho se servirá el desayuno, porque a las nueve saldremos con el vía crucis. Cuando anunciaron que el desayuno estaba servido, los hombres, las mujeres y los jóvenes iniciaron una competencia para ingresar al comedor, ésta es una costumbre; nos sirvieron frijoles negros, cuatro tortillas, queso y café. El menú de todos los días. Después, algunos migrantes y otros voluntarios empezaron a ordenar las pancartas, el resto observaba. Salí junto a Pablo y José del comedor, nos íbamos a reunir, los tres fuimos voluntarios y conformábamos el equipo logístico. Nuestro trabajo consistió en pegar las pancartas de papel para indicar la ubicación de cada una de las estaciones durante la representación del vía crucis, las pancartas las pegaríamos en las principales avenidas de la ciudad de Ixtepec; recuerdo que el Jueves Santo elaboramos las pancartas con la ayuda de algunos migrantes, pero no habíamos trazado la ruta.

Eran las 9:Io de la mañana y el recorrido no estaba trazado, por esa razón junto a Pablo y José decidimos marcharnos. Llegamos a la calle Moctezuma. En esa carretera había muchas casas, paredes y postes del tendido eléctrico; sobre ellas decidimos ir pegando las pancartas. De repente, el celular de Pablo empezó a emitir sonidos, le llamaban para avisarnos que no podían retrasarse más. Debido al contratiempo, Pablo y José decidieron continuar pegando, yo regresé al albergue para indicar el recorrido. El camino que seguimos fue el siguiente: el vía crucis salió del albergue a las 9:33, marchó por la calle Moctezuma; en la avenida i6 de Septiembre, giró en el sentido izquierdo de la avenida. En la calle Isabel la Católica, giró a la izquierda para retornar por la calle Moctezuma hacia el albergue, ahí finalizó. Todo el evento duró cuatro horas.

Cuando regresé al albergue, noté que algunos participantes escuchaban las palabras de Josefina:

Las estaciones del vía crucis están ubicadas, acompañemos a Jesús. Este vía crucis lo haremos como Hermanos en el Camino; ustedes iniciaron un vía crucis cuando salieron de sus tierras. Somos pueblos dolientes y sufrientes al ser desplazados de 
nuestros países. Unámonos, seamos solidarios con nuestros hermanos migrantes que dejan su patria, familia y todo lo que tienen con la esperanza que Jesús un día resucite, así como un día no habrá fronteras. $\stackrel{8}{-}$

Con esas palabras se daba apertura al evento. Este vía crucis no era una gran movilización semejante a la del año 20I5. No éramos una multitud, la mayoría provenía de Centroamérica. Llegué a contabilizar noventa migrantes, junto con los voluntarios posiblemente fuimos cien. Para los migrantes parecía una actividad inesperada, pero estratégica; participar era una manera para negociar o agilizar la información sobre su situación migratoria con los voluntarios al interior del albergue.

Para mí, todo sucedía rápido. Una semana antes, desconocíamos los pormenores sobre el vía crucis; el día que Alejandro Solalinde llegó, supimos que había decidido dedicar la actividad a los migrantes afrodescendientes que provienen de Centroamérica y de otros países, pues, como él me compartió: "esto lo hace diferente a otros años, más cercana a un acto religioso que una expresión política".?

Aunque Alejandro insistió que esta decisión lo convertía en un acto más religioso, no dejaba de ser en esencia un acto fuertemente político. Junto a esta decisión, Alejandro pidió a un viejo amigo, llamado Wilmer, que personificara al Cristo negro. Wilmer había migrado de Haití para trabajar en México; como otros migrantes corrió con la mala fortuna de ser detenido en Escárcega, Campeche, por los agentes de migración, quienes lo condujeron al recinto de migración en Acayucan, Veracruz. En el lugar permaneció cinco meses, junto con cuatro migrantes cubanos, obtuvo la libertad el 27 de enero de 2013 , cuando el delegado estatal del Instituto Nacional de Migración de Veracruz, Rafael Pretelín Pouchoulén, otorgó al albergue

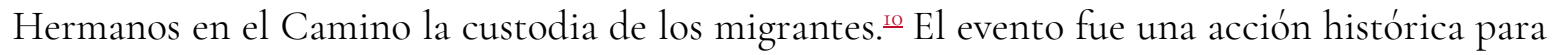
Alejandro y Elizabeth Rodríguez, directora del Centro de Derechos Humanos de la ciudad de Ixtepec, Oaxaca..$^{I}$ En el albergue, Wilmer decidió convertirse en voluntario mientras esperaba solucionar su situación migratoria. Una vez solucionada, abandonó el albergue. $\stackrel{\underline{12}}{ }$

Cuando empezamos a caminar, la procesión parecía un desorden social, cada uno caminaba cómodamente para cubrirse del sol. El caos no duró y cobró cierto orden: el Cristo negro (Wilmer) caminaba al frente, atrás iba Alejandro, Rodolfo, Francisca, María y Josefina. Los migrantes, los voluntarios, los policías que custodian ${ }^{13}$ a Alejandro ${ }^{\mathrm{I4}}$ fueron los últimos. María empezó a entregar las páginas de los himnos, ella quería que todos corearan los estribillos religiosos; ejecutó su guitarra como una animadora, después dijo: "vamos todos a cantar, perdón oh Dios mío". El himno les pareció desconocido, los que intentaron cantar sólo gesticularon murmullos.

Algunos cantaban mientras caminábamos por la calle Moctezuma. Vino la primera estación, con ésta las lecturas. Observé dos tipos de interacciones estrechamente vinculadas con el sentido político religioso, desde mi opinión, dirigidas principalmente a los migrantes. Las interacciones en cada estación parecían una secuencia de situaciones; Wilmer y al que le correspondía leer se alejaban de la multitud, el lector mencionaba el título de la estación, los migrantes junto a los 
voluntarios se convertían en los receptores que respondían. Seguidamente, el sujeto leía el Evangelio, hacía una explicación política de la lectura; ésta había sido previamente elaborada por la pastoral social de Alejandro y finalizaba con una oración para continuar la procesión.

Primera estación. Rodolfo y Wilmer se posicionaron frente a otros migrantes. Rodolfo procedió a leer el título de la estación, observó a las personas y empezó a decir: "Jesús es condenado a muerte. El empobrecimiento nos condena a migrar". La multitud respondió: "te adoramos, oh Cristo, y te bendecimos. Que por tu santa cruz redimiste al mundo". Después de la respuesta que los migrantes hicieron, él prosiguió:

Tomado del Evangelio de San Marcos, capítulo I5, versículo I5. "Pilatos, decidió agradar a la gente, les soltó a Barrabás y a Jesús lo entregó para que lo azotaran y lo crucificaran”. ¿Cuál es la meditación? La situación de pobreza por la que atraviesan nuestros países, provoca la expulsión natural de nuestros hermanos [...] Como personas de fe, tenemos que buscar formas concretas para transformar las realidades injustas, de manera que ningún ser humano se sienta forzado a migrar.

Dejó de leer y Josefina intervino pidiendo rezar un Padre Nuestro y una Ave María por todos los que se preparaban para migrar: "pedimos a Jesús, quien conoció la amargura de la emigración, que nos dé un corazón solidario para acoger a los migrantes que caminan buscando un mejor porvenir". Concluyeron sus palabras, se reagruparon y los cantos continuaron.

Cada vez que observaba a Rodolfo leer, pensaba cómo se había convertido en lector. A los días siguientes del vía crucis, le pregunté sobre su papel, me respondió que todo había surgido por una equivocación. El Martes Santo, Josefina, lo eligió. Ella tenía la responsabilidad de seleccionar a los lectores para cada una de las estaciones del Vía Crucis del Migrante. Después continuó explicándome cómo fue elegido:

Francisca leía unas hojas y le pregunté qué leía, ella me comentó que iba participar en el vía crucis; y me preguntó: ¿vos podés leer? Sí, le dije. Si quieres puedo leer. Pero sólo fue una insinuación, una broma. Pero empecé a leer. ¡Sí puedes!, mañana debes ayudarnos, me respondió ella, ¿a qué?, le pregunté, a leer en el vía crucis. Le respondí que no, porque no soy católico; soy evangélico. Pero Josefina me escuchó leer en ese momento y me dijo: ¡mira!, lees bien, ayúdanos mañana a leer en las estaciones. Me quedé sorprendido, en el momento no dije nada, después le dije: mire, voy hacerlo, pero debe decirme qué voy a leer y explicarme el proceso, porque no conozco lo que harán. Así fue como leí en las estaciones. No me simpatizan los católicos, pero colaboré en vez de perder mi tiempo. ${ }^{15}$

La procesión siguió y nos paramos en la segunda estación, Rodolfo se distanció del grupo para leer. Wilmer lo siguió. En sus manos tomó la guía de las lecturas y empezó a mencionar: "Jesús carga la cruz y se dirige al calvario. El migrante sale por necesidad: el éxodo del campo a la ciudad por falta de tierra y oportunidades". Enseguida, continuó diciendo: 
En la meditación observamos como nuestros hermanos y hermanas migrantes repiten hoy este calvario en busca de un trabajo y un futuro mejor para ellos y sus familias [...] El migrante se ve obligado a cargar la cruz del maltrato, la soledad, la discriminación, el racismo, la xenofobia, la explotación y de las políticas y leyes migratorias restrictivas.

Cuando Rodolfo concluyó, las personas se reagruparon para seguir en procesión. Simultáneamente, Francisca, una migrante salvadoreña, ordenaba sus hojas para leer la tercera estación. Caminamos cien metros y dijo: "Jesús cae por primera vez. El migrante es despreciado y humillado". Todos respondieron: "que por tu Santa Cruz redimiste al mundo". Después, mencionó que la lectura que iba a leer estaba retomada del libro del profeta Isaías, capítulo 53, versículos 3-5. En la lectura, Francisca enunciaba que Jesús fue: "despreciado y evitado por la gente [...]. ¿Cuál es la meditación?, "los migrantes también son traicionados, violados en sus derechos fundamentales, muchas veces por sus mismos paisanos y amigos".

Terminada la tercera estación, seguimos caminando. Nos detuvimos cuando llegamos a la cuarta estación, estábamos más cerca de la avenida principal de la ciudad de Ixtepec, el calor era más intenso, se percibía en las ropas sudorosas de los que caminábamos. Aun así, Rodolfo leyó el título de la estación, y les repitió: "Jesús encuentra a su madre, una madre que ama, un misterio de la vida. Te adoramos, oh Cristo, y te bendecimos". Continuó con las siguientes palabras:

en el Evangelio de San Lucas 2, 34-35 observamos como Simeón los bendijo y dijo a María, la Madre. Mira, este niño está colocado de modo que todos en Israel o caigan o se levanten; será signo de contradicción y así se manifestarán claramente los pensamientos de todos. La lectura habla del empobrecimiento y éste tiene un rostro concreto en las mujeres. El número de mujeres migrantes en nuestros países se ha incrementado.

En la lógica del diálogo, Josefina le siguió con las palabras: "recemos un Padre Nuestro y una Ave María por todas las mujeres migrantes que no consiguen un puesto de trabajo".

Seguimos caminando, en la quinta estación llegamos a la interconexión con la avenida i6 de Septiembre, cerca del mercado municipal, Wilmer se sentó para escenificar la primera caída de Jesús, los pocos habitantes de Ixtepec que nos observaban se admiraron con el Jesús negro. Con esa atención, Rodolfo procedió a leer el capítulo 27, versículo 32 de Mateo, elevó la voz y dijo: "a la salida encontraron un hombre de Cirene, llamado Simón, y lo forzaron a cargar la cruz". Al finalizar la lectura del Evangelio tomó con ambas manos las páginas, repitió: "En el camino del migrante se presentan muchos falsos amigos que con un gesto de amistad o con palabras acogedoras, traicionan aprovechando la situación por la que atraviesan, conduciéndolos a la delincuencia, la prostitución forzada, la explotación laboral (la trata de personas)".

Su voz quedó en silencio para seguir el vía crucis. Llegamos a la avenida i6 de Septiembre para realizar la sexta estación. Inmediatamente, Gonzalo se dirigió a todos para leer el Salmo i6, I5, y empezó a decir: "y yo, por mi inocencia, veré tu rostro, al despertar me saciaré de tu presencia. 
La meditación de la lectura es la siguiente: las leyes deben de respetar la dignidad humana y apegarse estrictamente a los convenios y tratados internacionales".

El camino en la avenida i6 de Septiembre fue corto, la marcha giró en la calle Isabel la Católica para regresar al albergue, en esta calle iniciamos con la séptima estación: el relato de la segunda caída de Jesús. El tema de la estación hablaba de cómo los refugiados y desplazados también son víctimas de la persecución. La lectura se había retomado del libro del "Profeta Isaías 53, 6". En ella se relataba que las personas pueden errar como ovejas, pero el Señor carga siempre con los pecados, el sufrimiento de las personas. Un sufrimiento que es ocasionado por la exclusión y las dificultades para acceder a los derechos básicos de los seres humanos.

Francisca concluyó para continuar caminando. Frente a unos viejos apartamentos se realizó la octava estación, el título fue el drama humano que se refleja en la experiencia migrante. Francisca se separó y esperó en silencio para leer Lucas 23, 27-28, comentó dos escenas en el relato, la primera, personificaba el llanto y la solidaridad de las mujeres con Jesús. La segunda, decía: "mujeres de Jerusalén, no lloren por mí; lloren más bien por ustedes y por sus hijos". En la interpretación que Rodolfo leyó enfatizó tres aspectos: la esperanza de las mujeres que despiden a sus hijos migrantes, el deseo del reencuentro y la soledad que sienten las madres cuando se alejan de sus hijos por la migración.

Nos volvimos a reunir y empezamos a caminar, cada vez estábamos más cerca del albergue. Josefina se mostraba cansada como todos, Wilmer parecía fatigado por el peso de la cruz y el calor. Los cantos eran silenciosos, pocos cantaban. Con esas impresiones nos paramos en la novena estación, Francisca empezó a hablar de la tercera caída de Jesús y la relación que existe con "el rostro humano del migrante". Ése era el tema. Leyó Mateo ir, 28. Francisca concluyó, todo parecía normal, la marcha continuó sin imaginar que podríamos coincidir con el vía crucis litúrgico de la ciudad de Ixtepec. Ninguno esperaba este imprevisto, ambos vía crucis coincidieron en la calle Isabel la Católica, los voluntarios fueron a consultarle a Alejandro qué se debía hacer, éste se mostró pensativo porque no deseaba confrontar con la institucionalidad religiosa y decidió que nos desviáramos.

Aceptamos la propuesta e hicimos un giro en la calle Oaxaca para interconectarse con la calle Moctezuma. Ahí nos detuvimos para hacer la décima estación. Rodolfo continuó hablando sobre el tema de la estación, se apresuró a leer Mateo 27, 35-36. La lectura relataba el juego y la repartición de ropa de Jesús después de su muerte. La relación con la experiencia de los migrantes era el siguiente: "El cuerpo de muchos es considerado como objeto de comercio para ser vendidos y traficados por los grupos del crimen organizado que operan impunemente en los países de tránsito de migrantes". Finalizó y seguimos.

Faltaba poco para concluir, el panorama que se observaba seguía siendo silencioso. Los migrantes no se sentían identificados totalmente con lo que estaban haciendo, algunos voluntarios no éramos diferentes al espíritu de los migrantes, carecíamos de emotividad. Caminamos para llegar a una vieja casa donde estuvo el Centro Cultural de España, realizamos la décima primera estación, en este momento la escena del vía crucis cambiaba, habíamos pasado 
simbólicamente del acompañamiento a la muerte y crucifixión de Jesús. La escena no fue emotiva y Wilmer siguió representando a un Cristo carente de expresividad. Esta vez Francisca leyó Lucas 23, 33. La lectura describía la crucifixión de Jesús, la interpretación del texto refería como en muchos lugares el migrante al igual que Jesús es crucificado mediante la discriminación, injusticias, explotaciones y humillaciones.

Cada vez estábamos más cerca del albergue. Llegamos a la décima segunda estación, Rodolfo se paró frente a nosotros y nos dijo: "Jesús muere en la cruz. El migrante es puesto en igualdad con los que son considerados despreciados". Continuo:

era medio día; se ocultó el sol y todo el territorio quedó en tinieblas hasta media tarde. El velo del santuario se rasgó por el medio. Jesús gritó con voz fuerte: Padre, en tus manos encomiendo mi espíritu. Dicho esto, expiró. La meditación nos dice que Jesús muere en la indiferencia [...] En esta estación recordamos a los migrantes que mueren en las calles sin trabajo, salud, ni derechos.

Los presentes sólo escuchábamos. Esto no incomodaba a nadie, el calor y el hambre sí. Proseguimos para realizar la décima tercera estación, Rodolfo habló de cuando Jesús fue bajado de la cruz. El pasaje bíblico se relacionó con la frase: "Refugio para los migrantes". Guardamos silencio porque sabíamos que Rodolfo leería Juan i9, 38. El Evangelio hablaba sobre José de Arimatea, el discípulo clandestino de Jesús, quien pidió permiso a Pilatos para llevarse el cuerpo de Jesús. La meditación que Rodolfo leyó nos narraba como las personas pueden dejar el egoísmo para dar acogida y espacio a los migrantes por el mundo. La idea estaba retomada del versículo 25 de Mateo: "Yo era migrante y ustedes me acogieron".

La décima cuarta estación. Rodolfo y Wilmer se ubicaron frente a nosotros, habló sobre el título de la estación: Jesús es sepultado. La lectura se fundamentó en Mateo 27, 59-60; hacía mención a la muerte de Jesús como producto de un camino de sufrimientos, de esa misma forma, decía Rodolfo: "el migrante soporta el sufrimiento, la muerte, todo el dolor humano por el amor a la familia, por los sueños y por los ideales”.

Esta estación, en mi opinión, encierra el argumento central en el que Alejandro y algunos voluntarios han construido el sentido de la violencia y sufrimiento en el migrante. A diferencia del camino de Jesús, el camino de los migrantes representa una muerte continua infligida por la violencia social e institucional. La décima quinta estación fue distinta, Wilmer retomó el papel central, se dirigió discursivamente a los que participábamos en el vía crucis. Con la siguiente narrativa:

Yo como ustedes conozco qué significa caminar hacia un sueño [...] En algunas estaciones del vía crucis hablamos de ayudar, como cuando ayudaron a levantar la cruz a Jesús. Quiero decir que cada uno de nosotros debe aprender a ayudar a otros en el camino. Ahora, estamos experimentando momentos difíciles en nuestras vidas, así como nosotros, a la raza negra que camina por México no la quieren reconocer, como si no existieran. Estamos observando situaciones de racismo, pero el racismo 
ha pasado a otro nivel porque no se discrimina sólo por el color, también, por ser inmigrante, como no eres un ser humano. [...] Espero que ese Jesús les pueda ayudar a cada uno de ustedes, porque también fue inmigrante. Desde niño cuando nace Jesús lo querían matar, ¿qué hace María?, huyó hacia Egipto, ahí estuvo Jesús de inmigrante, ilegal como nosotros hoy [...] Por eso, los dejo con Dios en el corazón de cada uno de ustedes que sigue adelante, porque Dios siempre defiende a los inmigrantes. Dios los va a ayudar para que ustedes logren sus sueños. Buena suerte a cada uno de ustedes y les deseo lo mejor en su camino. $\frac{16}{}$

La ventana: los actos y las narrativas

El objetivo de mostrar una lectura sobre los usos políticos del sufrimiento no debe ser mal interpretada, creyendo que es un fin exhibicionista de la violencia. Al contrario, a través de las narrativas situadas se pueden rastrear formas en que los migrantes, activistas interpretan o explican sus experiencias con la violencia, además, son acciones que buscan legitimar que sus derechos están siendo vulnerados. En este sentido, narrar los asesinatos, desapariciones, extorsiones, secuestros plantea problemas que aluden y no se pueden separar de diversos públicos sociales: agentes de migración, agentes federales, policías municipales, distintas sociedades, etcétera.

Las oraciones que enunció Rodolfo en la primera estación: "Jesús es condenado a muerte"; "como personas de fe, tenemos que buscar formas concretas para transformar las realidades injustas, de manera que ningún ser humano se sienta forzado a migrar" son ventanas para mapear la explicación de los problemas. Por medio de las palabras de Rodolfo, no se trata de describir situaciones; al contrario, está enunciando acciones (Austin 1996, 4I que buscan sensibilizar a diversos públicos, aunque las respuestas no siempre pueden ser inmediatas. No obstante, el acto de la narración es esencial para la exposición de las singularidades de sus problemas (Fassin 2005. $\underline{2 \mathrm{IO}})$.

"Jesús es condenado a muerte", traza diversos aspectos. Hace evidente que el nuevo sujeto crucificado es el migrante. Estos enunciados recurren a un marco de tiempo y espacio sagrado para ubicarlo, que al igual que Jesús atravesó caminos donde fue vulnerado. Apelar a este marco sagrado conlleva intenciones morales que buscan conectar el presente de violencias que se ejercen sobre los migrantes en una relación con la historia sagrada, el propósito no sólo es evidenciar las injusticias, también, consiste en mostrar que las violencias juegan un papel fundamental como una organización espacio-temporal que hasta cierto punto puede ser natural en la vida social de los migrantes (Dick 20IO, 279). Esta violencia criminal se ha caracterizado por violaciones sexuales, trata de personas, asesinatos, secuestros, robos, extorsiones. La cual no se aleja de los procesos sociales de la violencia institucional estrechamente relacionada con las políticas de control de las fronteras (Salazar 20I2, Aikin y Anaya 20I3, Anguiano 20I4, Treviño 2016) y la política mexicana contra el narcotráfico (Marengo 20I5). Éste es el escenario de Rodolfo, así como de otros migrantes centroamericanos irregulares. 
Como contraparte a este escenario, el enunciado "como personas de fe, tenemos que buscar formas concretas para transformar las realidades injustas, de manera que ningún ser humano se sienta forzado a migrar", ofrece posibles salidas al problema que encuentra diálogos con el pensamiento de la teología de la liberación que se practicó en países como El Salvador. Sin embargo, de maneras distintas, en El Salvador, el enunciado "transformar las realidades injustas" fue una manera de asumir compromisos políticos y sufrir violencias con el fin de crear un tipo de sociedad distinta. Este principio, englobaba sentido de comunidad que transcendía al individuo mismo (Peterson y Peterson 2008, 5I2). En este tiempo-espacio de México, el enunciado agrega otros significados. No busca transformar las realidades injustas en sentido amplio, en el acto se está enunciando que "no es una lucha por cambiar el sistema [...], con su necesidad de inclusión, cada nueva generación de indocumentados reactualiza esas luchas por el reconocimiento a su derecho a tener derechos (Rocha 20I7, 23).

"Yo como ustedes conozco qué significa caminar hacia un sueño". Es una manera en la que Wilmer, no sólo reconoce que caminar hacia un sueño es una manera de pensar la transformación social. Wilmer, por medio del "yo", está mostrando a los migrantes que tiene la capacidad de plantearse como sujeto (Benveniste I986, I8I), en el acto enuncia el pasado de sus sufrimientos y los vincula con el espacio-tiempo presente de los migrantes que están en el albergue y con el presente de las migraciones en general. Wilmer al igual que los migrantes que estaban frente a él se posicionó como alguien que también ha sufrido. Al hacerlo, dirige su enunciación a los migrantes, éstos se convierten en el público directo. Y en el espacio-tiempo los ubica como los protagonistas que se caracterizan por sufrir violencias. Wilmer se define y los define como personas que han vivenciado experiencias traumáticas. Pero, también, "caminar hacia un sueño" traza una secuencia de espacialidad, de pensar en progreso y cambio de situaciones sociales. El "sueño" parece que dibuja un escenario de éxito social.

A estos protagonistas, Wilmer también los coloca dentro de una historia sagrada para explicar las situaciones de violencia social e institucional, al decir: "cuando nace Jesús lo querían matar, ¿qué hace María?, huyó hacia Egipto, ahí estuvo Jesús de inmigrante, ilegal como nosotros hoy". Este enunciado, es una manera de calibrar la historia de Wilmer con la historia sagrada. La calibración es una manera de crear relaciones señaladas o indexicadas entre eventos de signos, de modo que un evento de signo actual se vuelve interpretable en relación con un evento de signo anterior (Eisenlohr 2006 et al., Dick 2010).

En esta indexicalidad, Wilmer ubica el problema del sufrimiento al enunciar que la migración indocumentada se ha estigmatizado, observándolos como "criminales", terroristas, sujetos sin derechos. Estos valores, pueden ser entendidos como formas que pueden matar a los hombres, mujeres y jóvenes centroamericanos. Una manera de evitar este sufrimiento, se plantea a través del movimiento. "Huyó hacia Egipto" es una idea progresiva de plantearse metas u horizontes en los cuales podrán ser "libres del sufrimiento" y de quienes se los infligen. Aunque, este discurso de Wilmer no plantea puntos intermedios, la dirección parece que muestra la "muerte" como la razón del movimiento que inicia el desplazamiento y "estar como inmigrante" se muestra como el fin del viaje, no así del sufrimiento. Pero, "estar como migrante", si se deja de lado el enunciado "huyó a Egipto", como la imagen de Estados Unidos, "estar como migrante" 
puede leerse como una imagen que no representa un lugar concreto y cobran sentido las acciones que están dentro del Vía Crucis del Migrante.

"Estar como migrante" es una exposición de sí y de su sufrimiento, con este enunciado, dentro del acto discursivo de Wilmer, se forma, manifiesta y se reivindican derechos desde su posición (Fassin 2005, 2I2). Su relato se dirige a la solidaridad social, también al reconocimiento de sus derechos políticos y sociales. "Estar como migrantes" es una manera de ponerse metas; en el contexto del tránsito por México significan asegurar mecanismos de sobrevivencia en un ambiente hostil. Además, "estar como migrantes" busca en su mayoría construir, en el marco de una retórica que pretende ser bien fundada y convincente, un vínculo entre su situación social y las alteraciones de su cuerpo (Fassin 2005, 213), que han sido ocasionadas por transitar caminos donde han sido vulnerados sus derechos.

\section{Reflexiones}

Las reflexiones que ofrezco en este documento sobre los usos políticos del sufrimiento que se expone por medio del cuerpo y narrativas en el Vía Crucis del Migrante es un marco sobre el cual no he dado por finalizada esta investigación. Más allá de proponer conclusiones, las reflexiones continuarán con el propósito de establecer comparaciones analíticas entre dos Vía Crucis del Migrante: en Ixtepec y el de San Salvador, El Salvador.

\section{Bibliografía}

AIKIN, Olga y Alejandro ANAYA. 20I3. "Crisis de derechos humanos de las personas migrantes en tránsito por México; redes y presión transnacional”. Foro Internacional 53(I): I43-I8I.

ANGUIANO, María. 20I4. "Introducción. Migrar en tiempos adversos. Control de fronteras, crisis económicas y vulnerabilidad humana". En Migraciones internacionales. Crisis y vulnerabilidades. Perspectivas comparadas, ed. María Anguiano, II-44. Tijuana: El Colegio de la Frontera Norte.

AUSTIN, John. I996. Cómo hacer cosas con las palabras. Barcelona: Paidós.

BAJTÍN, Mijaíl. 1982. "El problema de los géneros discursivos". En Estética de la creación verbal, 248-293. México: Siglo XXI.

BECKETT, Greg. 20I7. "A Dog's Life: Suffering Humanitarism in Port-au-Prince, Haiti". American Anthropologist ing(I): 35-45.

BENVENISTE, Émile. I986. "De la subjetividad en el lenguaje". En Problemas de la lingüística general, I79-I87. México: Siglo XXI.

BERNAL, Victoria. 20I7. "Diaspora and the Afterlife of Violence: Eritrean National Narratives and What Goes Without Saying". American Anthropologist irg(I): 23-34. 
CALLEROS, Juan. 2013. "Seguridad pública y seguridad humana en la migración indocumentada de tránsito por México". Foro Internacional53(2): 317-336.

CASILLAS, Rodolfo. 1989. "Una nueva aurora para las utopías religiosas: líneas de análisis de sus contenidos sociales". Frontera Norte I(I): I75-195.

CELAM. 2008. "Capítulo 8, Reino de Dios y romoción de la dignidad humana". En V Conferencia General del Episcopado Latinoamericano y del Caribe. Documento conclusivo, del Consejo Episcopal Latinoamericano Aparecida: CELAM.

CORBIN, Alain. 2005. "Capítulo 2. El dominio de la religión". En Historia del cuerpo. Volumen 2. De la revolución francesa a la gran guerra, ed. Jean Courtine y Georges Vigerell. Traducido por María José Hernández y Alicia Martorell Paloma Gómez, 57-83. México: Taurus.

DAS, Veena. 2008a. "Sufrimientos, teodiceas, prácticas disciplinarias y apropiaciones". En Sujetos del dolor, agentes de dignidad, ed. Francisco Ortega, 437-459. Bogotá: Universidad Nacional de Colombia-Facultad de Ciencias Humanas, Pontificia Universidad Javeriana, Instituto Pensar.

2008b. "Lenguaje y cuerpo: transacciones en la contrucción del dolor". En Sujetos del dolor, agentes de dignidad, ed. Francisco Ortega, 343-375. Bogotá: Universidad Nacional de Colombia-Facultad de Ciencias Humanas, Pontificia Universidad Javeriana, Instituto Pensar.

DICK, Hilary. 20io. "Imagined lives and modernist chronotopes in Mexican nonmigrant discourse". American Ethnologist 37(2): 275-290.

EISENLOHR, Patrick. 2006. Little India: Diaspora, Time, and Ethnolinguistic Belonging in Hindu Mauritius. Berkeley: University of California Press.

FASSIN, Didier. 1999. "La patetización del mundo. Ensayo de antropología política del sufrimiento". En Cuerpo, diferencias y desigualdades, ed. Mara Viveros y Gloria Garay, 3I-4I. Bogotá: Centro de Estudios Sociales CES.

2005. "Gobernar por los cuerpos, políticas de reconocimeinto hacia los pobres y los inmigrantes". Educação, año XXVIII(2) (mayo y agosto 2005): 20I-226.

20ro. "El irresistible ascenso del derecho a la vida. Razón humanitaria y justicia social". Revista de Antropologia Social (I9): I9I-204.

GÉLIS, Jaques. 2005. "Capítulo i. El cuerpo, la iglesia y lo sagrado". En Historia del cuerpo. Del renacimiento al siglo de las luces. Volumen I. Traducido por Núria Petit y Mónica Rubio, 27-III. México: Taurus. 
HERNÁNDEZ, Miguel. 20I4. "La experiencia social de la responsabilidad moral por el otro en los circuitos trashumantes de la pastoral migrante México-Estados Unidos". Metapolítica i8(85): 65-71.

IZCARA, Simón. 20i2. "Violencia contra inmigrantes en Tamaulipas". European Review of Latin American and Caribbean Studies (93): 3-24.

MARENGO, Jorge. 2015. "Fronteras elásticas, hegemónicas y teoría del discurso: la frontera sur de México". Revista CIDOB (in): 9-3.

PETERSON, Anna y Brandt PETERSON. 2008. "Martyrdom, Sacrifice, and Political Memory in El Salvador". Social Research: An International Quarterly 75(2): 5II-542.

ROCHA, José. 20I7. La desobediencia de las masas. La migración no autorizada de centroamericanos a Estados Unidos como desobediencia civil. San Salvador: UCA Editores.

ROMIZI, Francesco. 20I3. "Modelos multiculturales de la Iglesia católica en la pastoral migratoria. Los casos contrapuestos de los ecuatorianos en Barcelona y New York". En XXXV

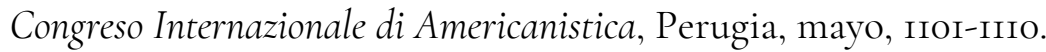

SALAZAR, Sergio. 20i2. "Violencia y criminalización de la migración centroamericana en México: perspectivas de investigación". Anuario Centro de Investigación y Estudios Políticos (3): I80-223.

SALDAÑA, Iván. 20ı2. “El padre Solalinde regresa con escolta oficial?”. Excélsior, in de julio de 2012, www.excelsior.com.mx/2012/o7/II/nacional/847037 (Fecha de consulta: i2 de abril de 2016).

SECALLA, Rafael. 20or. "Origenes del aprovechamiento de la Semana Santa Andaluza". Filosofía, política y economía en el Laberinto (6): 93-I03.

SENTÍES LABORDE, Francisco Javier, coord. 20I4. Hermanos en el camino. Experiencias de amor desde el infierno de la migración. Guadalajara: ITESO, Universidad Iberoamericana León.

SOBRINO, Jon. 2009. Fuera de los pobres no hay salvación. Segunda edición. San Salvador: UCA Editores.

TORRECILLAS, Antonio. 2009. "Jesús Nazareno, El de las llaves, sagrado protector de la comunidad de religiosas clarisas de la ciudad de Guadix". Boletín del Centro de Estudios Pedro Suárez: Estudios sobre las comarcas de Guadix, Basa y Huéscar (22): 269-282.

TREVIÑO, Javier. 20i6. “¿De qué hablamos cuando hablamos de la 'securitización' de la migración internacional en México?: una crítica”. Foro Internacional 56(2): 253-29I 
VERDUGO, Rosa y Águeda GÓMEZ. 2006. "Narraciones políticas y procesos de enmarcamiento del discurso de las asociaciones del Foro para la Integración Social de los Inmigrantes de España". Papers (8I): I49-I69

VILLAFUERTE, Daniel. 20I7. Tiempo de fronteras. Una visión geopolítica de la frontera sur de México. Primera edición. Tuxtla Gutiérrez: UNICACH.

VOGT, Wendy. 2013. "Crossing Mexico: Structural Violence and the Commodification of Undocumented Central American Migrants". AE American Ethnologist 40(4): 746-780.

\section{Notas}

I En el artículo retomo algunas ideas de la investigación "Experiencias y los usos del sufrimiento. El caso del Vía Crucis del Migrante, Ixtepec, Oaxaca (20r6)", que realicé durante la maestría en El Colegio de Michoacán.

2 Es un activista y sacerdote diocesano; defensor de los derechos humanos de los migrantes; coordinador de la Pastoral de la Movilidad Humana Pacífico Sur del Episcopado Mexicano. En el año 2007 fundó el albergue para migrantes Hermanos en el Camino, en la ciudad de Ixtepec, Oaxaca. Él, al igual que fray Tomás, se ha caracterizado por ser organizador de distintos vía crucis del migrante en diversos lugares del sur de México y en la ciudad de Ixtepec desde el año 2007 .

3 Alejandro Solalinde, entrevista personal, albergue Hermanos en el Camino, Ixtepec, Oaxaca, 23 de marzo de $20 i 6$.

4 He conocido que la representación de los vía crucis del migrante no es exclusividad de Ixtepec, a la vez, conozco que existen otros personajes importantes en esta temática como fray Tomás del albergue de la 72, en Tenosique, Tabasco; anteriormente el padre Heyman en Arriaga, Chiapas y los Misioneros de San Carlos Borromeo Scalabriniano, en Tijuana. No obstante, para fines de este documento he decidido centrarme sólo en el caso del vía crucis del migrante en Ixtepec.

5 Seminario de Avances de Investigación, 27 de abril de 20i6. Ideas tomadas de los comentarios que hizo el Dr. Miguel Hernández M.

6 Alejandro Solalinde, entrevista personal, albergue Hermanos en el Camino, Ixtepec, Oaxaca, 23 de marzo de 2016.

7 Alejandro Solalinde, entrevista personal, albergue Hermanos en el Camino, Ixtepec, Oaxaca, 23 de marzo de $20 i 6$.

8 Josefina, audio personal, albergue Hermanos en el Camino, Ixtepec, Oaxaca, 23 de marzo de 2016.

Relaciones Estudios de Historia y Sociedad, vol. XL, núm 157, 2019 
9 Alejandro Solalinde, entrevista personal, albergue Hermanos en el Camino, Ixtepec, Oaxaca, 23 de marzo 20i6. El diálogo que aparece en el párrafo se ha tomado de la entrevista.

Io El Universal, "INM da a Solalinde custodia de migrantes de Cuba y Haití, domingo 27 de enero de 2013 .

II Reconstrucción de la historia de Wilson a partir del libro de Francisco Javier Sentíes Laborde. coord. Hermanos en el camino. Experiencias de amor desde el infierno de la migración (Guadalajara: ITESO, Universidad Iberoamericana León, 2014).

I2 Wilmer Martiel, entrevista personal, albergue Hermanos en el Camino, Ixtepec, Oaxaca, 26 de marzo de 2016.

I3 En abril de 20r2, Alejandro Solalinde recibió amenazas de muerte de dos hombres. Se refugió en algunos países de Europa e interpuso una demanda en Amnistía Internacional México. En el mes de julio regresó para incorporarse nuevamente a la dirección del albergue Hermanos en el Camino; a la vez, Marisela Morales, directora de la Procuraduría General de la República, le asignó cuatro guardaespaldas de tiempo completo para su protección.

I4 Iván Saldaña, “El padre Solalinde regresa con escolta oficial?", Excélsior, in de julio de 20I2, www.excelsior.com.mx/20I2/07/II/nacional/847037 (Fecha de consulta: I2 de abril 20i6).

I5 Rodolfo Ardón, entrevista personal, albergue Hermanos en el Camino, Ixtepec, Oaxaca, 29 de marzo de 2016.

I6 Wilmer Martiel, entrevista personal, albergue Hermanos en el Camino, Ixtepec, Oaxaca, 26 de marzo de 2016.

\section{Yuri Arón Inocente Escamilla}

Maestro en Ciencias Sociales en el área de Estudios Rurales, Centro de Estudios Rurales (CER), El Colegio de Michoacán. En la actualidad, pertenece al Programa de Doctorado en Ciencias Sociales Especialidad Estudios Rurales, de El Colegio de Michoacán. Adscrito a la línea: vida pública, movilidades y enajenaciones contemporáneas. 